\title{
Effects of d-Amphetamine on Temporal Control in a Peak-Interval Procedure in Lewis and Fischer 344 Rats
}

\author{
Meagan E. Follett
}

Follow this and additional works at: https://researchrepository.wvu.edu/etd

\section{Recommended Citation}

Follett, Meagan E., "Effects of d-Amphetamine on Temporal Control in a Peak-Interval Procedure in Lewis and Fischer 344 Rats" (2014). Graduate Theses, Dissertations, and Problem Reports. 7312.

https://researchrepository.wvu.edu/etd/7312

This Thesis is protected by copyright and/or related rights. It has been brought to you by the The Research Repository @ WVU with permission from the rights-holder(s). You are free to use this Thesis in any way that is permitted by the copyright and related rights legislation that applies to your use. For other uses you must obtain permission from the rights-holder(s) directly, unless additional rights are indicated by a Creative Commons license in the record and/ or on the work itself. This Thesis has been accepted for inclusion in WVU Graduate Theses, Dissertations, and Problem Reports collection by an authorized administrator of The Research Repository @ WVU. For more information, please contact researchrepository@mail.wvu.edu. 
Effects of $d$-Amphetamine on Temporal Control in a Peak-Interval Procedure in Lewis and Fischer 344 Rats

Meagan E. Follett

\author{
Thesis submitted \\ To the Eberly College of Arts \& Sciences \\ at West Virginia University \\ in partial fulfillment of the requirements for the degree of \\ Master of Science in \\ Psychology/Behavior Analysis
}

Karen G. Anderson, Ph.D., Chair Elizabeth Kyonka, Ph.D.

Steven Kinsey, Ph.D.

Department of Psychology

Morgantown, West Virginia

2014

Keywords: Lewis, Fischer 344, Temporal Control, $d$-Amphetamine, Peak Interval

Copyright 2014 Meagan E. Follett 


\begin{abstract}
All rights reserved
INFORMATION TO ALL USERS

The quality of this reproduction is dependent upon the quality of the copy submitted.

In the unlikely event that the author did not send a complete manuscript and there are missing pages, these will be noted. Also, if material had to be removed,

a note will indicate the deletion.
\end{abstract}

UMI 1554830

Published by ProQuest LLC (2014). Copyright in the Dissertation held by the Author.

Microform Edition (c) ProQuest LLC.

All rights reserved. This work is protected against

unauthorized copying under Title 17, United States Code

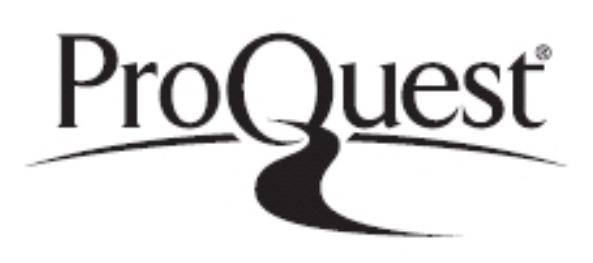

ProQuest LLC.

789 East Eisenhower Parkway

P.O. Box 1346

Ann Arbor, MI $48106-1346$ 


\begin{abstract}
Effects of $d$-Amphetamine on Temporal Control in a Peak-Interval Procedure in Lewis and Fischer 344 Rats
\end{abstract}

Meagan E. Follett

The present study assessed temporal control in LEW and F344 rats using a peak-interval procedure, in which fixed-interval (FI) trials were randomly presented with peak-interval (PI) trials, during which the interval was extended and no reinforcement was delivered. The peak time, or the average time at which response rates were the highest, was compared to the FI value as a measure of temporal control across three FI/PI conditions (10/30, 30/90, 60/180 seconds). There were no significant differences in temporal control as assessed by the PI procedure between LEW and F344 rats across three different conditions as well as following acute administration of $d$-amphetamine. On FI trials, LEW and F344 rats responded differentially across conditions, although there was no main effect of strain. The contingencies of the PI procedure may be so powerful that they override differential effects between these two strains, making it an insensitive measure, although the results of the present study indicate that sensitivity to temporal variables may be exerting some influence over differences in impulsive choice between LEW and F344 rats. 


\section{Table of Contents}

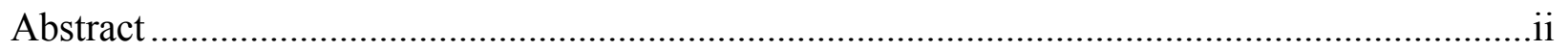

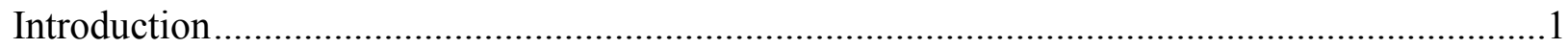

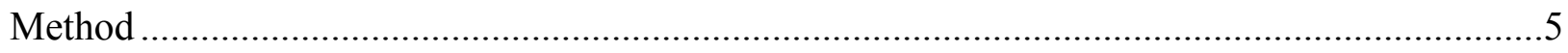

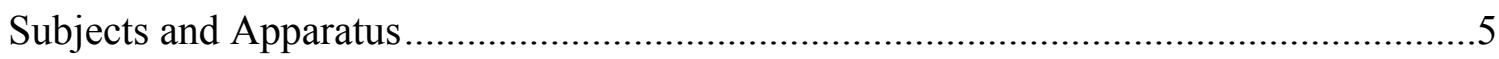

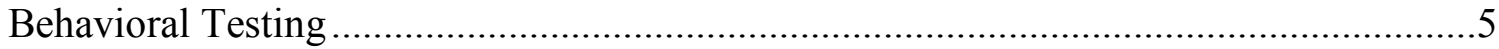

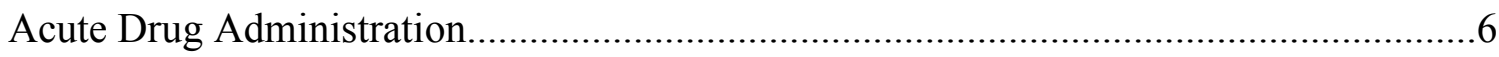

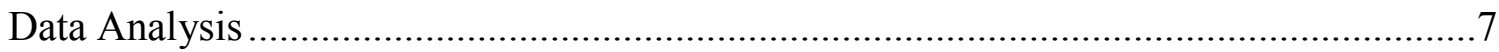

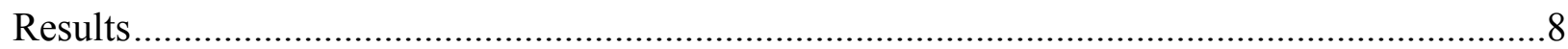

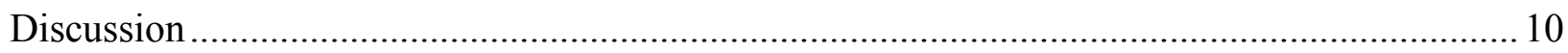

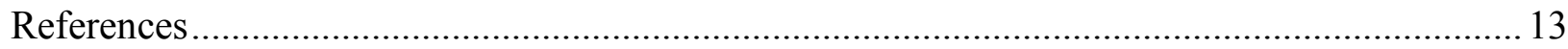

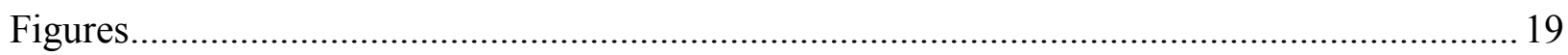

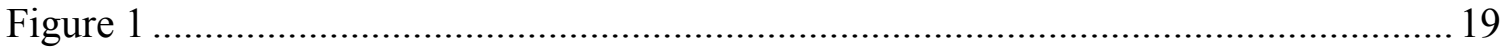

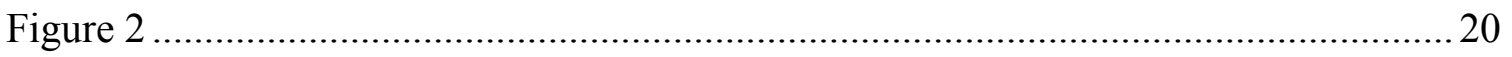

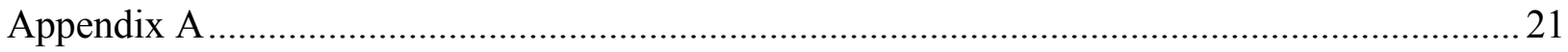

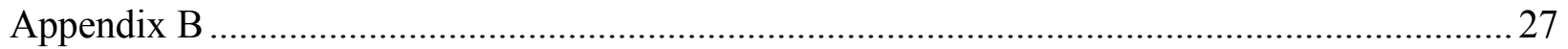


Effects of $d$-Amphetamine on Temporal Control in a Peak-Interval Procedure in Lewis and Fischer 344 Rats

Impulsive choice has been correlated with disorders such as attentiondeficit/hyperactivity disorder (ADHD), pathological gambling, and substance abuse (American Psychiatric Association, 2000; Evenden, 1999; Evenden \& Ryan, 1996; Perry \& Carroll, 2008). Experimental analysis of impulsive choice often involves a choice between a smaller, more immediate reinforcer versus a larger, more delayed reinforcer (e.g., Anderson \& Woolverton, 2005; Diller et al., 2008; Logue, 1988; Mazur, 1987). Such procedures are commonly referred to as delay-discounting procedures. When the delay to both reinforcers is short, the larger reinforcer is usually chosen. As the delay to the larger reinforcer increases, choice switches to the smaller, more immediate reinforcer (e.g., Mazur, 1987).

The switch from the larger to smaller reinforcer as the delay to the larger reinforcer increases may be conceptualized as a preference reversal (Ainslie \& Herrnstein, 1981). When given a choice between a standard and varying magnitude of reinforcement, choice for the variable key increases as the duration of reinforcement on that key increases (Neuringer, 1967). This indicates that preference reversals can occur due not only to changes in reinforcer delay, but also due to changes in reinforcer magnitude. Given that both delay and magnitude are manipulated within session in a delay-discounting procedure, both sensitivity to reinforcer delay and sensitivity to reinforcer magnitude could be possible behavioral mechanisms that may account for differences in self-controlled choice (Madden, 2008; Pitts, 2014).

\section{Lewis and Fischer 344 Rats and the Role of Neurochemistry}

The roles of genetic and behavioral factors on impulsive choice have been examined by comparing different rat strains. In recent years, studies have examined differences in impulsive choice between Lewis (LEW) and Fischer 344 (F344) rats, two inbred strains of rats with known 
neurochemical differences (Burnet et al., 1996; Flores et al., 1998; Moscary \& Bradberry, 1996; Selim \& Bradberry, 1996). LEW rats have fewer dopamine (DA) receptors and DA transporters in various regions of the brain than F344 rats (Flores et al., 1998). LEW rats also have lower levels of serotonin (5-HT) and fewer 5-HT transporters in various regions of the brain than F344 rats (Burnet et al., 1996; for a summary see Huskinson et al., 2012, Table 1). Past studies have implicated low levels of DA and 5-HT as factors that may increase impulsive choice (Cardinal et al., 2003; Sagvolden et al., 1998).

Although disparities in DA and 5-HT systems may underlie differences in delay discounting, it is unclear whether the behavioral mechanism for this difference among LEW and F344 rats involves a change in sensitivity to reinforcer magnitude or reinforcer delay. In a within-session delay-discounting procedure, LEW rats make fewer self-controlled choices than F344 rats (Anderson \& Diller, 2010; Anderson \& Woolverton, 2005; Huskinson \& Anderson, 2012; Huskinson et al., 2012). In the first block of trials where the delay to both reinforcers is 0 s, all rats, regardless of strain, choose the larger reinforcer on almost every trial, suggesting that LEW and F344 rats may not be differentially affected by the magnitude of the reinforcers, although only one set of magnitude values (1 versus 3 food pellets) was assessed (Madden et al., 2008). When food is delayed by $20 \mathrm{~s}$ in a response-acquisition procedure, more LEW than F344 rats acquire the lever-pressing response (Anderson \& Elcoro, 2007). Taken together, these recent data suggest the differences in delay discounting seen in LEW and F344 rats may be due to differences in temporal control. To date, there have been no studies that have examined temporal control in LEW and F344 rats. 


\section{Evaluation of Temporal Control}

Multiple procedures have been used to assess temporal control. Among these are the differential reinforcement-of-low-rate (DRL) schedule, the temporal-bisection task, the fixedinterval (FI) schedule, and the peak-interval (PI) procedure (Catania, 1970; Roberts, 1981). In a DRL schedule, only responses occurring greater than a specified interresponse time (IRT), or time between two consecutive responses that exceed the schedule requirement are reinforced (Catania, 1970; Ferster \& Skinner, 1957). In a temporal-bisection task, subjects are trained to discriminate between a short and long duration of a stimulus (tone, illumination of a key light, etc.) by making one response following the short-duration stimulus and another following the long-duration stimulus. Subjects are then presented with stimuli of intermediate lengths and "short" and "long" responses are recorded (Church \& Deluty, 1977; Orduña et al., 2011).

In an FI schedule, the first response after a fixed amount of time has passed is reinforced. PI trials are probe trials in which the length of the interval is extended, and responding is not reinforced (e.g., Orduña et al., 2008). The PI procedure allows for all of the benefits of the FI procedure, plus the added advantage of measuring responding as the scheduled time passes the interval value (Lejeune \& Wearden, 2006; Orduña et al., 2008). On PI trials, responding tends to increase as time to the next reinforcer decreases, but also tends to decrease as time moves past the scheduled interval value (Kaiser, 2009; Lejeune \& Wearden, 2006; Orduña et al., 2008). The peak time, or the average time at which response rates are the highest within PI trials, can be compared to the FI value as a measure of temporal control.

\section{d-Amphetamine, Delay Discounting, and Temporal Control}

Low levels of DA and 5-HT may contribute to higher rates of delay discounting (Cardinal et al., 2003; Kheramin et al., 2004; Mobini et al., 2000; Zeeb et al., 2010). Thus, drugs that alter 
levels of these neurotransmitters may affect delay discounting (Anderson \& Diller, 2010; Anderson \& Woolverton, 2005; Huskinson et al., 2012). Studies of stimulant drugs such as $d$ amphetamine, a drug that increases levels of DA and 5-HT (i.e., a monoamine agonist), on delay discounting are varied. Some report increases in delay discounting after stimulant drug administration (Charrier \& Thiebot, 1996; Evenden \& Ryan, 1996), while others report decreases in delay discounting following stimulant drug administration (Wade et al., 2000; Winstanley et al., 2003). Using a concurrent-chains choice procedure in order to separate the relative effects of sensitivity to reinforcer delay and amount following administration of methamphetamine, results from some subjects indicate a decrease in sensitivity to reinforcer delay, while others indicate a decrease in sensitivity to reinforcer amount (Pitts \& Febbo, 2004). It is possible that the administration of stimulant drugs may result in changes in sensitivity to both reinforcer delay and reinforcer amount, and that the effect obtained depends on which if these two opposing effects is more readily expressed under the particular experimental conditions (Pitts, 2014). Increases in self-controlled choice have been found for LEW, but not F344 rats following acute administration of $d$-amphetamine (Huskinson et al., 2012). These results indicate a possible relation between strain differences and effects of drugs, such as $d$-amphetamine, on impulsive choice.

The neurotransmitters 5-HT and DA have also been implicated in temporal control (Matell et al., 2006; Taylor et al., 2007), as multiple studies report a leftward-shift in the PI function, or an earlier peak time, for both rats and pigeons following administration of $d$ amphetamine and other monoamine agonists (Buhusi \& Meck, 2002; Frederick \& Allen, 1996; Meck, 1983; Maricq et al., 1981; Saulsgiver et al., 2006). Rightward-shifts in the PI function, or later peak times, have been reported following administration of DA antagonists (Frederick \& 
Allen, 1996). Comparisons among rats with known neurochemical differences on a PI procedure following acute administration of $d$-amphetamine may help to further elucidate the role of DA and other monoamines on temporal control.

\section{Method}

Subjects and Apparatus. Six experimentally naïve, male LEW rats and six experimentally naïve, male F344 rats were used as subjects. All subjects were housed in a colony room where temperature and humidity were maintained at constant levels and a reverse 12-hour dark-light cycle was in effect (lights on at 6:00 p.m.). All sessions were conducted at approximately the same time seven days per week, during the dark phase of the dark-light cycle. Subjects were fed approximately $12 \mathrm{~g}$ of rat chow one half hour after each experimental session, resulting in approximately 22 hours food restriction before the start of each session. Standard operant-conditioning chambers with two retractable levers (MED Associates, St. Albans, VT, USA) that have been described elsewhere (Huskinson et al., 2012) were used.

Behavioral Testing. Following initial lever-press training, all subjects were exposed to three PI conditions that differed with respect to FI/PI values. Each condition remained in effect until peak time was stable, which was defined as a minimum of 10 sessions, with less than $15 \%$ variation in peak time over the last seven sessions. The acceptable range was obtained by calculating $15 \%$ of the mean peak time of the last seven sessions, followed by adding and subtracting this number from the mean. If the average peak time from each of the last seven sessions was within this range (mean $+15 \%$ to mean $-15 \%$ ), data were considered stable. The order of conditions was as follows: Condition 1 (FI 10 s, PI 30 s), Condition 2 (FI 30 s, PI 90 s), Condition 3 (FI 60 s, PI 180 s), and Condition 2 (reversal). Each session began with a 10-min blackout and consisted of 35 trials. 
The first five trials of each session were FI trials, followed by three blocks of 10 trials each. Each block consisted of seven FI and three PI trials. Trials within each block were pseduorandomly determined such that each PI trial was separated by at least one FI trial. All trials were separated by an inter-trial interval (ITI). During the ITI, the lever remained extended, and the houselight and cue light were turned off. The length of the ITI differed across conditions in order to maintain a maximum of $10-12 \%$ of the session time spent in ITI. The ITI was 5,10 , or $20 \mathrm{~s}$ in length, for Condition 1, 2, or 3, respectively.

During FI trials, the houselight and the cue light directly above the extended lever was lit. The active lever was counterbalanced such that three LEW and three F344 rats responded on the left lever, and the remaining subjects responded on the right lever. During reinforcer delivery, the cue light above the extended lever darkened, the houselight flashed with the delivery of one food pellet, and the ITI began. Responses made before the interval has elapsed were recorded, but had no other programmed consequence. If a response was not made within $10 \mathrm{~s}$ after the FI had elapsed, the trial was terminated, scored as an omission, and the ITI began. During PI trials, the cue light directly above the extended lever was lit. After the PI had elapsed, the cue light and houselight darkened, and the ITI began. No food was delivered on PI trials. Sessions ended following the third block of trials or after a maximum session time was met $(27,47$, or 80 min for Conditions 1, 2, and 3, respectively), whichever came first.

Acute Drug Administration. After each subject had been exposed to all three conditions and peak time was stable in the Condition 2 reversal, effects of $d$-amphetamine were assessed in the Condition 2 reversal (FI 30 s, PI 90 s). Mondays and Thursdays served as control days, and saline or $d$-amphetamine was administered via intraperitoneal (ip) injection on Tuesdays and Fridays. Prior to administration of $d$-amphetamine, saline was administered before at least two 
sessions and continued until there was no disruption in responding following the injection procedure. $d$-Amphetamine sulfate salt was dissolved in a $0.9 \%$ saline solution $(1.0 \mathrm{mg} / \mathrm{ml})$ and administered in an injection volume of $1.0 \mathrm{ml} / \mathrm{kg}$ in the following doses: 0.0 (saline), $0.1,0.3$, 1.0 , and $1.8 \mathrm{mg} / \mathrm{kg}$. All subjects received doses in an ascending order, starting with $0.1 \mathrm{mg} / \mathrm{kg}$. A minimum of two determinations of each dose was obtained, with more determinations if visual inspection of the data revealed significant variability.

\section{Data Analysis}

The primary dependent measure was peak time, or the time at which maximum responding occurred in each PI trial. Response rates were collected in 1-s bins for all trials. Peak rate was defined as the maximum response rate, or the response rate of the 1-s bin that contained the peak time. PI functions were generated by plotting response rate as a function of time within each interval, averaged across the last seven sessions. The spread of the PI function was calculated according to Cheng and Westwood (1993) by interpolating the points to the right and left of the peak time at which the response rate was $50 \%$ of the peak rate, followed by calculating the difference in time between these two points. For FI trials, quarter life (QL) was calculated by examining the time taken in each interval for the first one-fourth of the total number of responses in that interval to be emitted (Herrnstein \& Morse, 1957). Latency, or the time from stimulus onset to the first response, was also calculated for FI trials. Separate independent samples $t$-tests were conducted to assess differences between LEW and F344 rats on all dependent measures.

Response rates were then normalized to bins one-tenth of the FI size $(1,3$, or $6 \mathrm{~s}$ for Conditions 1, 2, and 3, respectively), and a mixed analysis of variance (ANOVA) with normalized bin (1-10) and condition (1-4) as the within-subjects factors and strain (LEW and F344 rats) as the between-subjects factor was conducted to assess differences in response rates 
on FI trials. Mixed ANOVAs with dose of $d$-amphetamine (control - $1.8 \mathrm{mg} / \mathrm{kg}$ ) as the withinsubjects factor and strain (LEW or F344) as the between-subjects factor were also conducted for all dependent measures. In multiple cases, Mauchly's test of sphericity was significant $(p s<.05)$, indicating that the variances of the differences between all bin combinations were unequal. To prevent an increase in the type-I error rate, Greenhouse-Geisser corrections on degrees of freedom were used for these variables.

\section{Results}

For all subjects, response rates increased as a function of time within the FI. During PI trials across all FI schedule values, an initial increase in responding followed by a decrease in response rates as time moved past the scheduled interval value was evident. These results indicate control by the FI requirement(s) across the conditions (Fig. 1). Average data are representative of all individual subjects (for individual subject data from baseline conditions, see Appendix A). It should be noted that for one F344 rat (MFF-6), there was no evidence of the typical PI response pattern after over 100 sessions in Condition 1, and this rat was excluded from all analyses for all conditions. There were no significant differences in peak time or peak rate between LEW and F344 rats across all conditions ( $p$ s $>.05)$. LEW rats $(M=30.83, S D=3.19)$ had a significantly larger spread of the PI function than F344 rats $(M=25.69, S D=3.37)$ in the Condition 2 Reversal (PI $90 \mathrm{~s}$ ), $t(9)=2.60, p<.05$. Peak response rates were significantly higher for LEW rats in the Condition 2 reversal than in Condition $2 t(5)=-2.895, p<.05$, whereas response rates for F344 rats remained relatively unchanged across Condition 2 and its reversal.

Response rates increased over the course of the interval for both LEW and F344 rats for all conditions, and this was confirmed by a significant main effect of bin, $F(1.09,9.83), p<$ 
$.001, \eta_{\mathrm{p}}{ }^{2}=0.85$. A significant main effect of condition was also found, $F(3,81), p<.001, \eta_{\mathrm{p}}{ }^{2}=$ 0.63 , indicating that for both strains, response rates increased as a function of condition, with higher response rates in conditions with higher FI values (Conditions 1-3). These main effects were qualified by a significant interaction between bin and condition, $F(2.22,9.83), p<.001$, $\eta_{\mathrm{p}}{ }^{2}=0.70$. The main effect of strain was nonsignificant $(p>.05)$, although LEW and F344 rats responded at different rates depending on condition, and this was evidenced by a significant interaction between condition and strain, $F(3,81), p<.05, \eta_{\mathrm{p}}{ }^{2}=0,27$. Interactions between bin and strain, as well as the 3-way interaction between condition, bin, and strain were nonsignificant $(p s>.05)$.

$d$-Amphetamine produced dose-dependent decreases in average peak time, peak rate, and spread of the PI function for both LEW and F344 rats, although there were no statistically significant differences between the two strains on any of these measures (Fig. 2, right panel; For individual subject data from acute administration of $d$-amphetamine, see Appendix B). A significant main effect of dose was found for peak time, $F(1.61,12.88)=24.91, p<.001, \eta_{\mathrm{p}}{ }^{2}$ $=.76$, peak rate, $F(1.71,13.68)=16.92, p<.001, \eta_{\mathrm{p}}{ }^{2}=.68$, and spread, $F(2.18,17.40)=20.30, p$ $<.001, \eta_{\mathrm{p}}{ }^{2}=.72$, which indicates a decrease in each dependent measure with increasing doses of $d$-amphetamine $(0.0 \mathrm{mg} / \mathrm{kg}$ to $1.8 \mathrm{mg} / \mathrm{kg})$. A similar effect of dose was found for QL, such that there were no statistically significant differences between LEW and F344 rats, but a significant main effect of dose was found, $F(1.92,15.37)=121.91, p<.001, \eta_{\mathrm{p}}{ }^{2}=.94$.

A dose-dependent decrease in latency to the first response following $d$-amphetamine administration was evident for both LEW and F344 rats, although no main effect of strain was found. There was a significant main effect of dose, $F(5,40)=25.89, p<.001, \eta_{\mathrm{p}}{ }^{2}=.76$, indicating that as the dose of $d$-amphetamine increased, latency to the first response decreased. 
This main effect was qualified by a significant interaction between strain and dose, $F(5,40)=$ $3.05, p<.05, \eta_{\mathrm{p}}{ }^{2}=.28$. Separate independent samples $t$-tests were conducted to identify the doses at which significant strain differences were present, and the $p$ value was adjusted to account for multiple comparisons by dividing the acceptable $p$ in half for each additional test conducted, resulting in an acceptable value of $p<.002$. On control days, LEW rats $(M=12.00$, $S D=1.94)$ had significantly shorter latencies to begin responding than F344 rats $(M=16.54, S D$ $=2.38)$. Following administration of $0.3 \mathrm{mg} / \mathrm{kg} d$-amphetamine, $\mathrm{LEW}$ rats $(M=6.45, S D=1.85)$ also had significantly shorter latencies to begin responding than F344 rats $(M=10.83, S D=$ 2.55).

\section{Discussion}

There were no significant differences in peak time between LEW and F344 rats across all conditions, and $d$-amphetamine did not differentially affect temporal control in these two strains of rats. The pattern of responding during FI and PI trials for all rats indicated control by the FI requirement across conditions, or essentially equivalent temporal control among LEW and F344 rats in the PI procedure. Response rates between LEW and F344 rats, however, did differ across all conditions, as evidenced by an interaction between strain and condition. It is possible that exposure to the longer FI value (60 s) may have affected responding by LEW and F344 rats in the Condition 2 Reversal (FI 30 s), as LEW rats had significantly higher FI response rates and a larger spread of the PI function than F344 rats in this condition. LEW rats also had significantly higher peak response rates in the Condition 2 Reversal than in Condition 2. These results may be conceptualized as more, yet less efficient responding for LEW rats in the Condition 2 Reversal compared to F344 rats as well as compared to LEW responding in Condition 2. Future work using longer FIs may further elucidate these effects. 
LEW rats also had significantly shorter latencies to begin responding on control days as well as following administration of $0.3 \mathrm{mg} / \mathrm{kg} d$-amphetamine. Latencies were reduced for both strains at higher doses (1.0 and $1.8 \mathrm{mg} / \mathrm{kg} d$-amphetamine), so it may have been beneficial to test intermediate doses (e.g., $0.56 \mathrm{mg} / \mathrm{kg} d$-amphetamine) as well. Decreases in the average latency to the first response in FI trials may be conceptualized as increases in premature responding. Similarly, $d$-amphetamine has been shown to increase premature and perseverative responding in rats on a 5-choice serial reaction time task (5-CSRTT) (Paterson et al., 2011; van Gaalen et al., 2006). A 5-CSRTT involves reinforcing responses to a lit aperture among a number of nose-poke apertures (Robbins, 2002). In this procedure, premature responding is defined as making a response prior to the illumination of an aperture, and perseverative responding is defined as repeated responses following the initial response that earns the reinforcer. Increases in premature and perseverative responding in the present procedure may be masking effects of sensitivity to delay in LEW and F344 rats.

Restricting responding to one per trial rather than multiple responses may limit the effects of premature and perseverative responding on temporal control. The use of a discrete-trials temporal-control procedure such as the temporal-bisection task may further elucidate differences in self-controlled choice between LEW and F344 rats. When a self-controlled choice is made in a delay-discounting procedure, it is followed by a delay prior to the delivery of a food pellet (e.g., Huskinson et al., 2012). It is possible that LEW and F344 rats differ in their ability to discriminate the length of these delays, which may affect choice. The use of a temporal-bisection procedure would allow for the assessment of possible differences in the ability to accurately discriminate the length of a stimulus (such as the delay to the reinforcer) in LEW and F344 rats. It is also possible that LEW and F344 rats differ in sensitivity to magnitude or that there is an 
interaction between sensitivity to magnitude and delay, which was not assessed in the present study. Future research on separating the effects of sensitivity to delay and magnitude in LEW and F344 rats at baseline as well as following administration of $d$-amphetamine may help to further elucidate the behavioral mechanism of differences between these two strains of rats in delay-discounting procedures.

In summary, there were no significant differences in temporal control as assessed by the PI procedure between LEW and F344 rats across three different conditions as well as following acute administration of $d$-amphetamine. It is possible that the behavioral mechanism for strain differences in a delay-discounting task between LEW and F344 rats could be sensitivity to magnitude, yet the results of the present study indicate that temporal variables may be exerting some influence. Examining effects of longer FIs and intermediate doses of $d$-amphetamine in using the current procedure may shed more light on temporal control in LEW and F344 rats in a PI procedure. It is also possible that the contingencies of the PI procedure are so powerful that they override differential effects between these two strains, making it an insensitive measure. Future research could be aimed at the use of a discrete-trials procedure such as the temporalbisection task, which may reveal differences in temporal control between the two strains, as well as further separating effects of reinforcer magnitude and delay on choice. 


\section{References}

Ainslie, G. \& Herrnstein, R.J. (1981). Preference reversal and delayed reinforcement. Animal Learning and Behavior, 9, 476-482.

American Psychiatric Association (2000). Diagnostic and statistical manual of mental disorders (4th ed., Text Revision). Washington, DC.

Anderson, K.G., \& Diller, J.W. (2010). Effects of acute and repeated nicotine administration on delay discounting in Lewis and Fischer 344 rats. Behavioural Processes, 21, 754-764.

Anderson, K.G., \& Elcoro, M. (2007). Response acquisition with delayed reinforcement in Lewis and Fischer 344 rats. Behavioural Processes, 74, 311-318.

Anderson, K.G., \& Woolverton, W. L. (2005). Effects of clomipramine on self-control choice in Lewis and Fischer 344 rats. Pharmacology, Biochemistry, and Behavior, 80, 387-393.

Buhusi, C.V., \& Meck, W.H. (2002). Differential effects of methamphetamine and haloperidol on the control of an internal clock. Behavioral Neuroscience, 116, 291-297.

Burnet, P.W., Mefford, I.N., Smith, C.C., Gold, P.W., \& Sternberg, E.M. (1996). Hippocampal 5-HT1A receptor binding site densities, 5-HT1A receptor messenger ribonucleic acid abundance and serotonin levels parallel the activity of the hypothalamo-pituitary-adrenal axis in rats. Behavioural Brain Research, 73, 365-368.

Cardinal R.N., Robbins T.W., \& Everitt B.J. (2003). Choosing delayed rewards: perspectives from learning theory, neurochemistry, and neuroanatomy. In: Heather, N., Vuchinich, R. (Ed.), Choice, behavioral economics and addiction. (pp. 183-213) Amsterdam.

Catania, A.C. (1970). Reinforcement schedules and psychophysical judgments: a study of some temporal properties of behavior. In W.N. Schoenfeld (Ed.), Theory of reinforcement schedules (pp. 1-42). New York: Appleton-Century-Crofts. 
Charrier, D., \& Thiébot, M.H. (1996). Effects of psychotropic drugs on rat responding in an operant paradigm involving choice between delayed reinforcers. Pharmacology, Biochemistry and Behavior, 54, 149-57.

Cheng, K., \& Westwood, R. (1993). Analysis of single trials in pigeons' timing performance. Journal of the Experimental Analysis of Behavior, 19, 56-67.

Church, R.M., \& Deluty, M.Z. (1977). Bisection of temporal intervals. Journal of Experimental Psychology, 3, 216-228.

Diller, J.W., Saunders, B.T., \& Anderson, K.G. (2008). Effects of acute and repeated administration of caffeine on temporal discounting in rats. Pharmacology, Biochemistry, and Behavior, 89, 546-555.

Evenden, J.L. (1999). Varieties of impulsivity. Psychopharmacology 146, 348-61.

Evenden, J.L., \& Ryan, C.N. (1996). The pharmacology of impulsive behavior in rats: the effects of drugs on response choice with varying delays of reinforcement. Psychopharmacology 128, 161-70.

Ferster, C.B., \& Skinner, B.F. (1957). Schedules of Reinforcement. New York: AppletonCentury-Crofts.

Flores, G., Wood, G.K., Barbeau, D., Quirion, R., \& Srivastava, K.L. (1998). Lewis and Fischer rats: a comparison of dopamine transporter and receptors levels. Brian Research, 814, 3440.

Frederick, D.L., Allen, J.D. (1996). Effects of selective dopamine D1- and D2-agonists and antagonists on timing performance in rats. Pharmacology Biochemistry and Behavior, 53, $759-764$. 
Herrnstein, R.J., \& Morse, W.H. (1957). Effects of pentobarbital on intermittently reinforced behavior. Science, 125, 929-931.

Huskinson, S.L., \& Anderson, K.G. (2012). Effects of acute and chronic administration of diazepam on delay discounting in Lewis and Fischer 344 rats. Behavioural Pharmacology, 23, 315-330.

Huskinson, S.L., Krebs, C.A., \& Anderson, K.G. (2012). Strain differences in delay discounting between Lewis and Fischer 344 rats at baseline and following acute and chronic aministration of d-amphetamine. Pharmacology, Biochemistry, and Behavior, 101, 403416.

Kaiser, D.H. (2009). Fewer peak trials per session facilitate acquisition of peak responding despite elimination of response rate differences. Behavioural Processes, 80, 12-19.

Kheramin, S., Body, S., Ho, M.Y., Velázquez-Martinez, D.N., Bradshaw, C.M., Szabadi, E., Deakin, J.F.W., \& Anderson, I.M. (2004). Effects of orbital prefrontal cortex dopamine depletion on inter-temporal choice: a quantitative analysis. Psychopharmacology, 175, 206-214.

Lejeune, H., \& Wearden, J.H. (2006). Scalar properties in animal timing: Conformity and violations. The Quarterly Journal of Experimental Psychology, 59, 1875-1908.

Logue, A.W. (1988). Research on self-control: An integrating framework. Behavioral and Brain Sciences 11, 665-709.

Madden, G.J., Smith, N.G., Brewer, A.T., Pinkston, J.W., \& Johnson, P.S. (2008). Steady-state assessment of impulsive choice in Lewis and Fischer 344 rats: Between-condition delay manipulations. Journal of the Experimental Analysis of Behavior, 90, 333-344. 
Maricq, A.V., Roberts, S., \& Church, R.M. (1981). Methamphetamine and time estimation. Journal of Experimental Psychology: Animal Behavior Processes, 7, 18-30.

Matell, M.S., Bateson, M., \& Meck, W.H. (2006). Single-trials analyses demonstrate that increases in clock speed contribute to the methamphetamine-induced horizontal shifts in peak-interval timing functions. Psychopharmacology, 188, 201-212.

Mazur, J. E. (1987). An adjusting procedure for studying delayed reinforcement. In M. L. Commons, J. E. Mazur, J. A. Nevin, \& H. Rachlin (Eds.), Quantitative analysis of behavior: The effect of delay and of intervening events on reinforcement value (pp. 5573). Hillsdale, NJ: Erlbaum.

Meck, W.H. (1983). Selective adjustment of the speed of internal clock and memory processes. Journal of Experimental Psychology: Animal Behavior Processes, 9, 171-201.

Mobini, S., Chiang, T.J., Al-Ruwaitea, A.S.A., Ho, M.Y., Bradshaw, C.M., \& Szabadi, E. (2000). Effects of central 5-hydroxytryptamine depletion on inter-temporal choice: a quantitative analysis. Psychopharmacology, 149, 313-318.

Moscary, Z., \& Bradberry, C.W. (1996). Effect of ethanol on extracellular dopamine in nucleus accumbens: comparison between Lewis and Fischer 344 rat strains. Brain Research, 706, 194-198.

Neuringer, A.J. (1967). Effects of reinforcement magnitude on choice and rate of responding. Journal of the Experimental Analysis of Behavior, 10, 417-424.

Orduña, V., Garcia, A., Menez, M., Hong, E., \& Bouzas, A. (2008). Performance of spontaneously hypertensive rats in a peak-interval procedure with gaps. Behavioural Brain Research, 191, 72-76. 
Orduña, V., Hong, E., \& Bouzas, A. (2011). Timing behavior in streptozotocin-induced diabetic rats. Behavioural Brain Research, 224, 189-194.

Paterson, N.E., Ricciardi, J., Wetzler, C., \& Hanania, T. (2011). Sub-optimal performance in the 5-choice serial reaction time task in rats was sensitive to methylphenidate, atomoxetine, and $d$-amphetamine, but unaffected by the COMT inhibitor tolcapone. Neuroscience Research, 69, 41-50.

Perry, J.L, \& Carroll, M.E. (2008). The role of impulsive behavior in drug abuse. Psychopharmacology, 200, 1-26.

Pitts, R.C. (2014). Reconsidering the concept of behavioral mechanisms of drug action. Journal of the Experimental Analysis of Behavior, in press, ePub ahead of print retrieved April 10, 2014 from http://onlinelibrary.wiley.com/doi/10.1002/jeab.80/abstract.

Pitts, R.C. \& Febbo, S.M. (2004). Quantitative analyses of methamphetamine's effects on selfcontrol choices: implications for elucidating behavioral mechanisms of drug action. Behavioural Processes, 66, 213-233.

Robbins, T.W. (2002). The 5-choice serial reaction time task: behavioural pharmacology and functional neurochemistry. Psychopharmacology, 163, 362-380.

Roberts, S. (1981). Isolation of an internal clock. Journal of Experimental Psychology: Animal Behavior Processes, 7, 242-268.

Sagvolden, T., Aase, H., Zeiner, P., \& Berger, D. (1998). Altered reinforcement mechanisms in attention-deficit: hyperactivity disorder. Behavioural Brain Research, 94, 61-71.

Saulsgiver, K.A., McClure, E.A., \& Wynne, C.D.L. (2006). Effects of d-amphetamine on the behavior of pigeons exposed to the peak procedure. Behavioural Processes, 71, 268-285. 
Selim, M. \& Bradberry, C.W. (1996). Effect of ethanol on extracellular 5-HT and glutamate in the nucleus accumbens and prefrontal cortex: comparison between the Lewis and Fischer 344 rat strains. Brain Research, 716, 157-164.

Taylor, K.M., Horvitz, J.C., \& Balsam, P.D. (2007). Amphetamine affects the start of responding in the peak interval timing task. Behavioural Processes, 74, 168-175.

Wade, T.R., de Wit, H., \& Richards, J.B. (2000). Effects of dopaminergic drugs on delayed reward as a measure of impulsive behavior in rats. Psychopharmacology, 150, 90-101.

Winstanley, C.A., Dalley, J.W., Theobald, D.E.H., \& Robbins, T.W. (2003). Global 5-HT depletion attenuates the ability of amphetamine to decrease impulsive choice on a delaydiscounting task in rats. Psychopharmacology, 170, 320-331.

Zeeb, F.D., Floresco, S. B., \& Winstanley, C. A. (2010). Contributions of the orbitofrontal cortex to impulsive choice: interactions with basal levels of impulsivity, dopamine signaling, and reward-related cues. Psychopharmacology, 211, 87-98.

van Gaalen, M.M., Brueggeman, R.J., Bronius, P.F.C., Schoffelmeer, A.N.M., \& Vanderschuren, L.J.M.J. (2006). Behavioral disinhibition requires dopamine receptor activation. Psychopharmacology, 187, 73-85. 


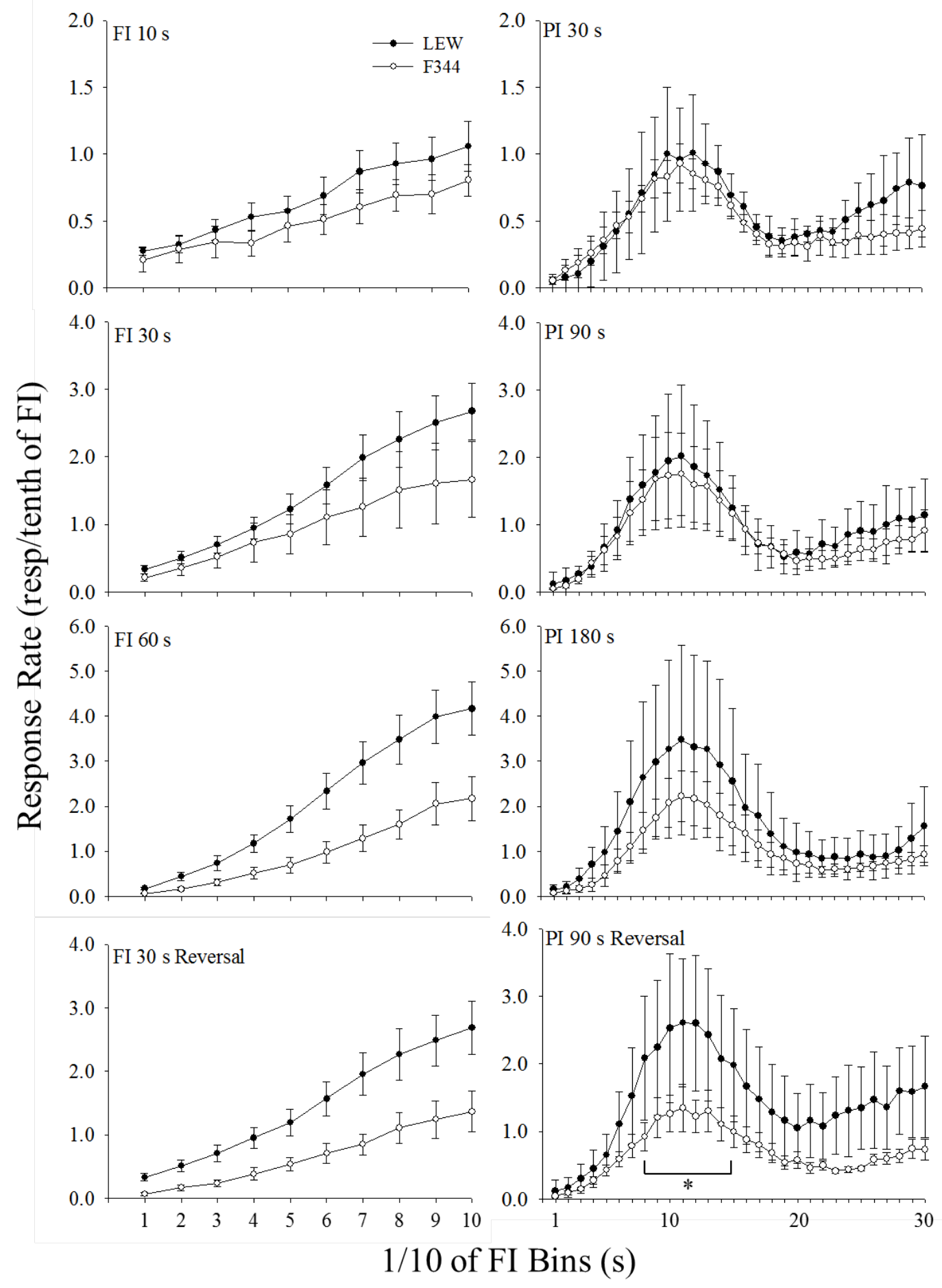

Figure 1, Normalized average response rates for LEW (filled symbols) and F344 (open symbols) rats as a function of time within the interval. Left-hand panels represent data from FI trials; righthand panels represent data from PI trials. Rows (top to bottom) represent Conditions 1, 2, 3, and the Condition 2 reversal (1, 3, and 6-s bins for Conditions 1-3). Error bars represent Standard error of the mean. Note: $\mathrm{y}$-axis scaling differs across conditions. Note: $*=p<.05$. 

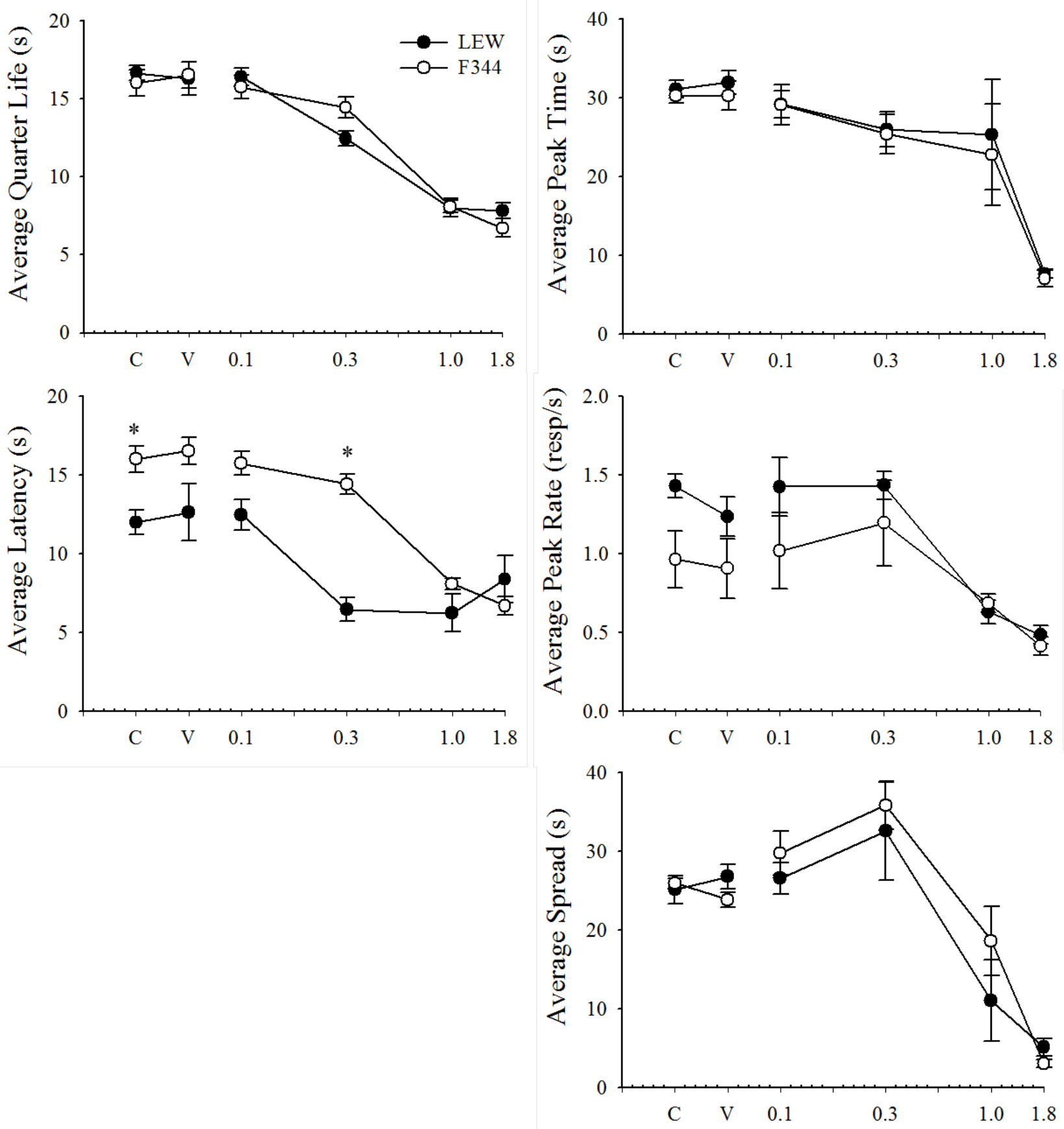

$d$-Amphetamine $(\mathrm{mg} / \mathrm{kg})$

Figure 2. Average dose-response functions for LEW (filled symbols) and F344 (open symbols) rats in the Condition 2 reversal. The left panel represents FI dependent measures of QL (top) and latency to first response (bottom) as a function of $d$-amphetamine dose. The right panel represents PI dependent measures of peak time, peak rate, and spread as a function of $d$ amphetamine dose. Error bars represent standard error of the mean. Note: $*=p<0.002$ 


\section{Appendix A}

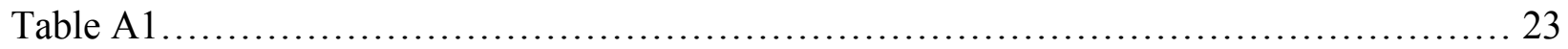

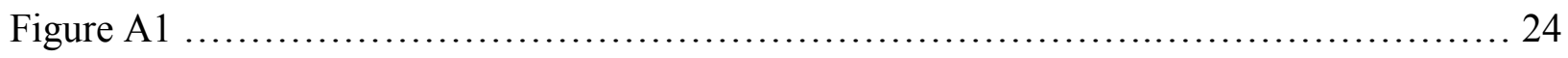

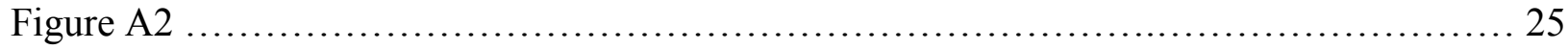

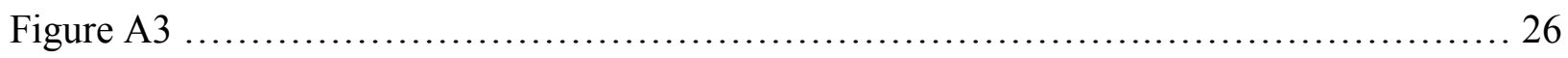

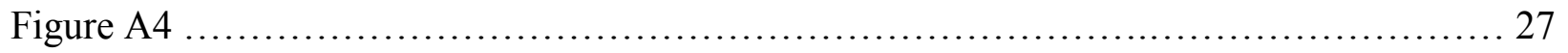




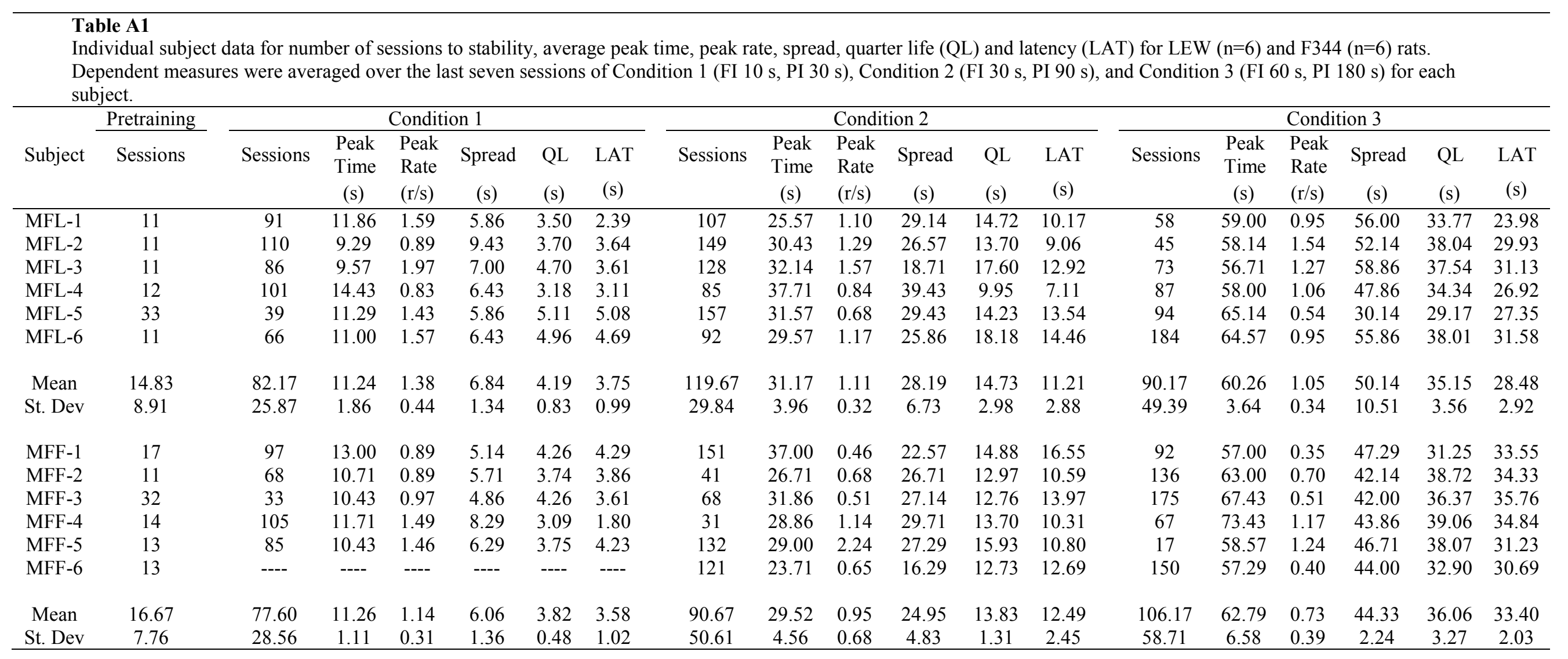




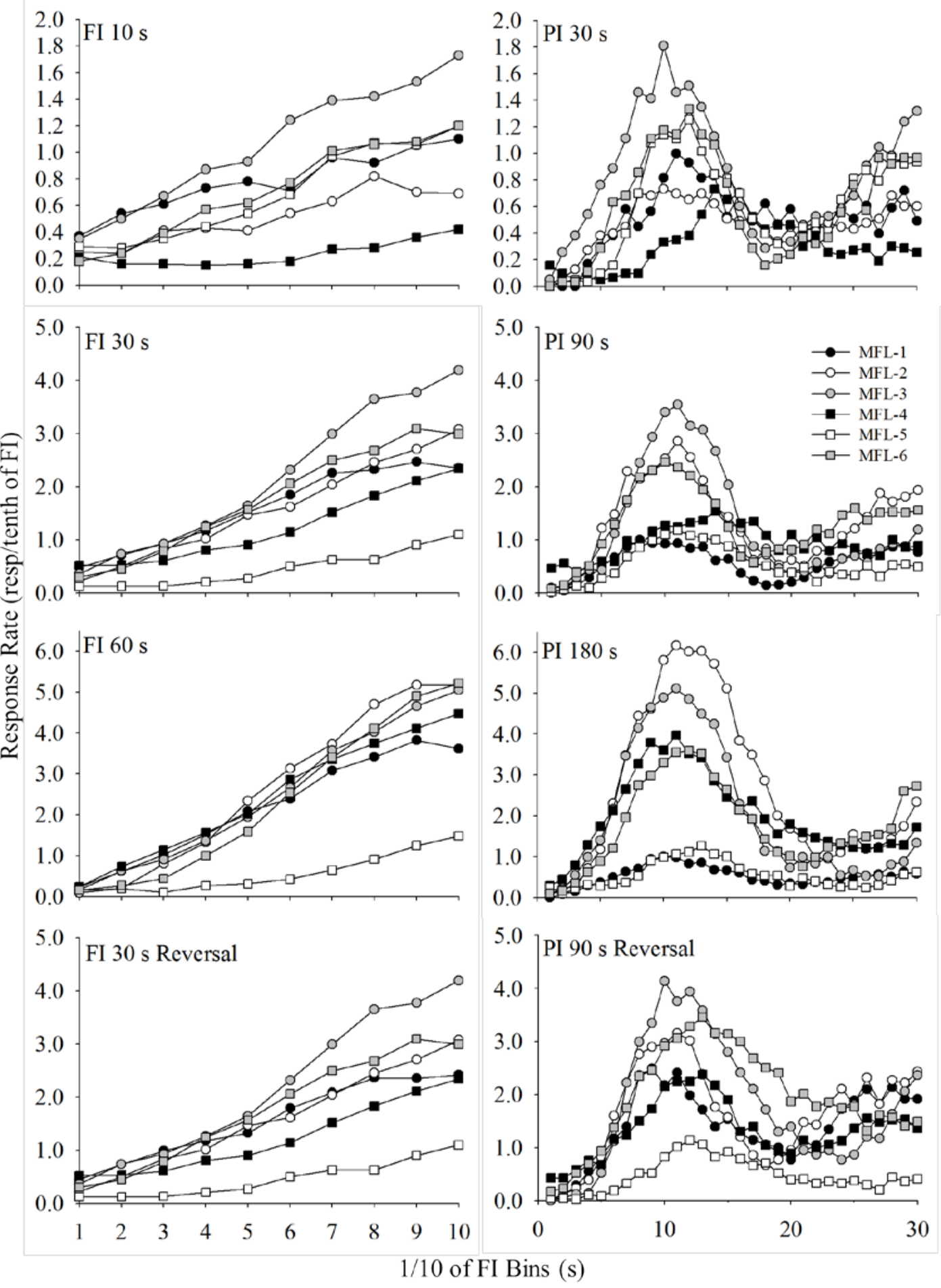

Figure A1. Normalized average response rates for individual LEW rats as a function of time within the interval. Left-hand panels represent data from FI trials; right-hand panels represent data from PI trials. Rows (top to bottom) represent Conditions 1, 2, 3, and the Condition 2 reversal (1,3, and 6-s bins for Conditions 1-3, respectively). Error bars have been removed for ease of viewing general response patterns. Note: $y$-axis scaling differs across conditions. 

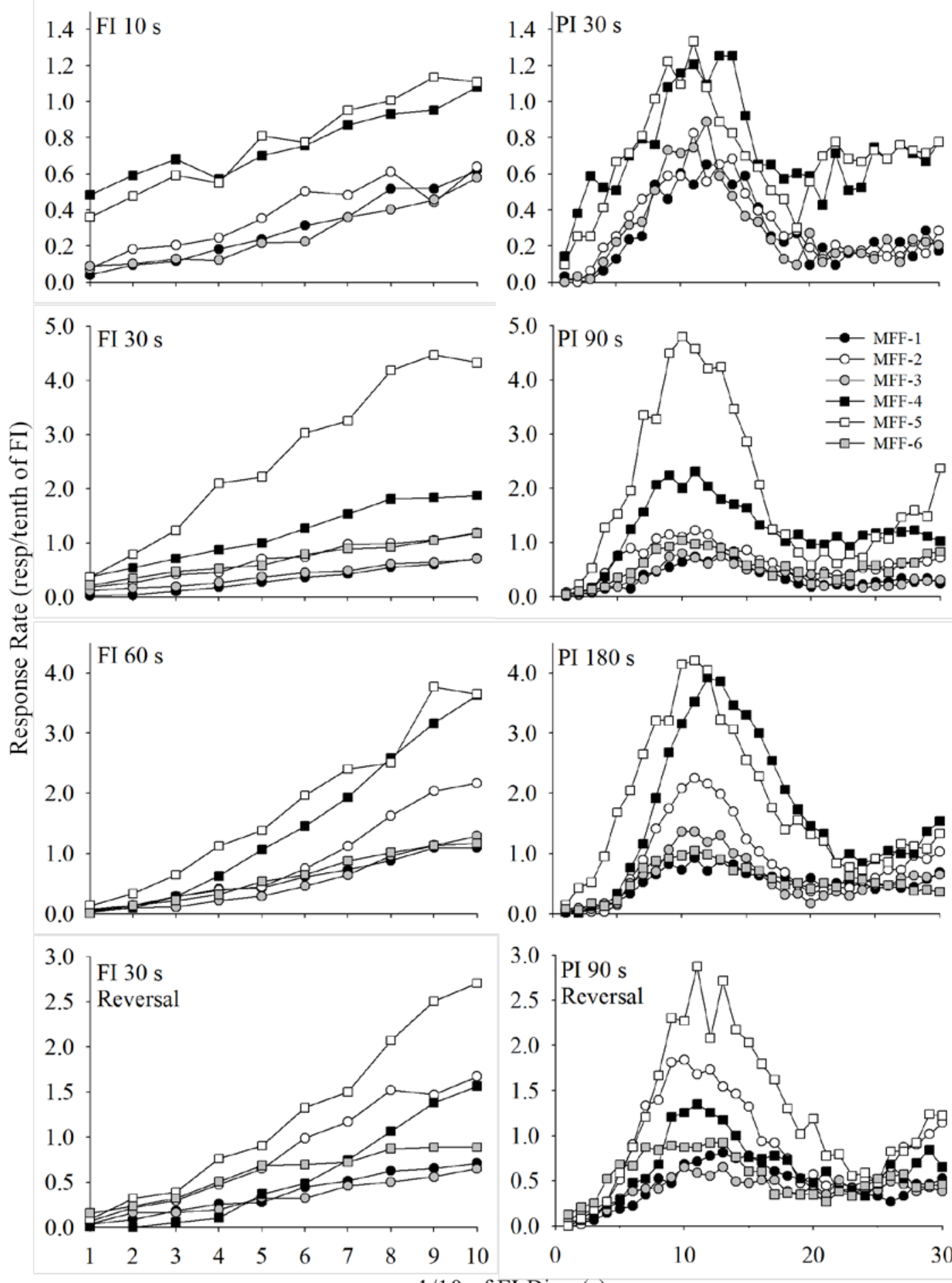

$1 / 10$ of FI Bins (s)

Figure A2. Normalized average response rates for individual F344 rats as a function of time within the interval. Left-hand panels represent data from FI trials; right-hand panels represent data from PI trials. Rows (top to bottom) represent Conditions 1, 2, 3, and the Condition 2 reversal (1, 3, and 6-s bins for Conditions 1-3, respectively). Error bars have been removed for ease of viewing general response patterns. Note: y-axis scaling differs across conditions. 

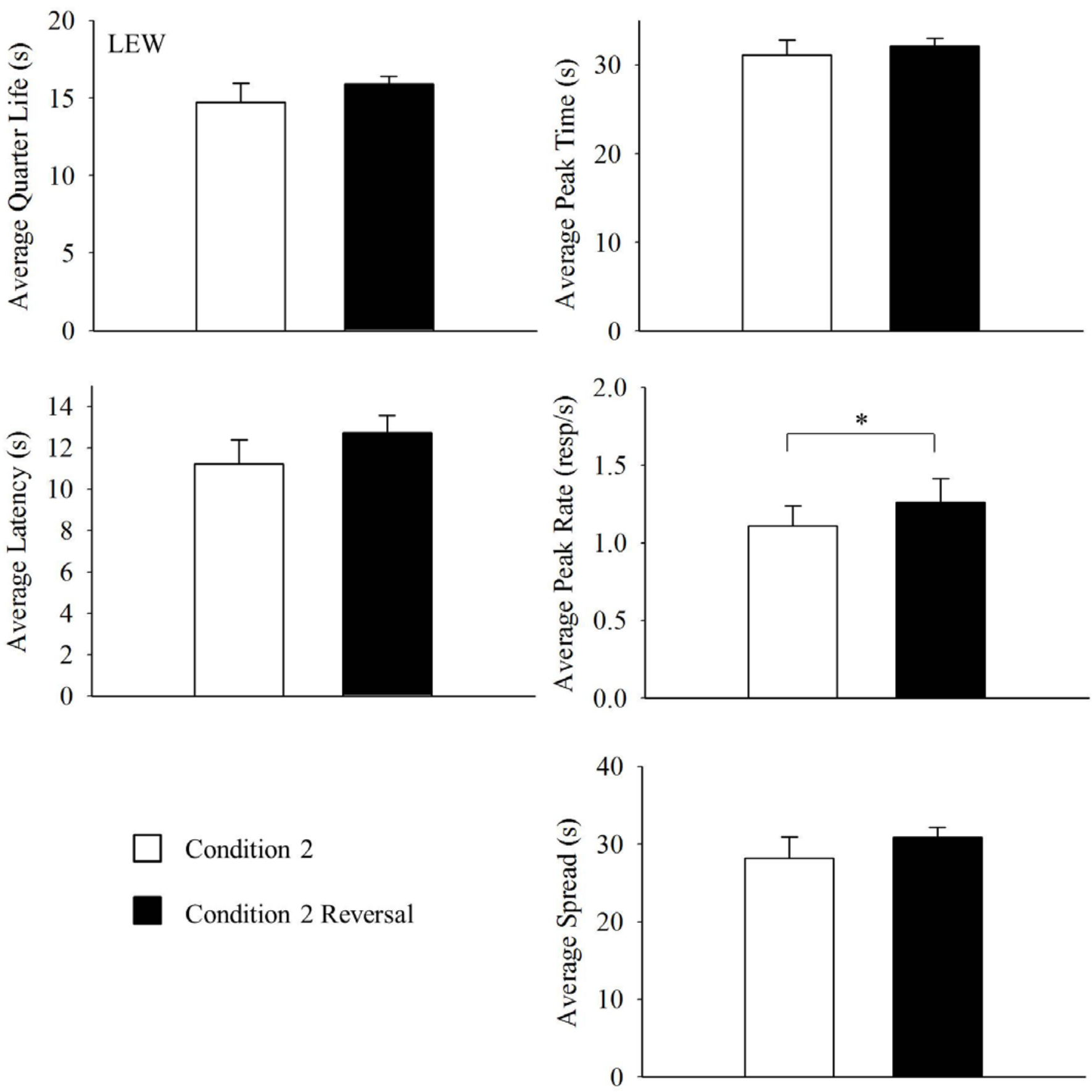

Figure A3. Average data for LEW rats in Condition 2 (white bars) and the Condition 2 Reversal (black bars). The left panel represents FI dependent measures of QL (top) and latency to the first response (bottom). The right panel represents PI dependent measures of peak time, peak rate, and spread. Error bars represent standard error of the mean. Note: y-axis scaling differs across measures. 

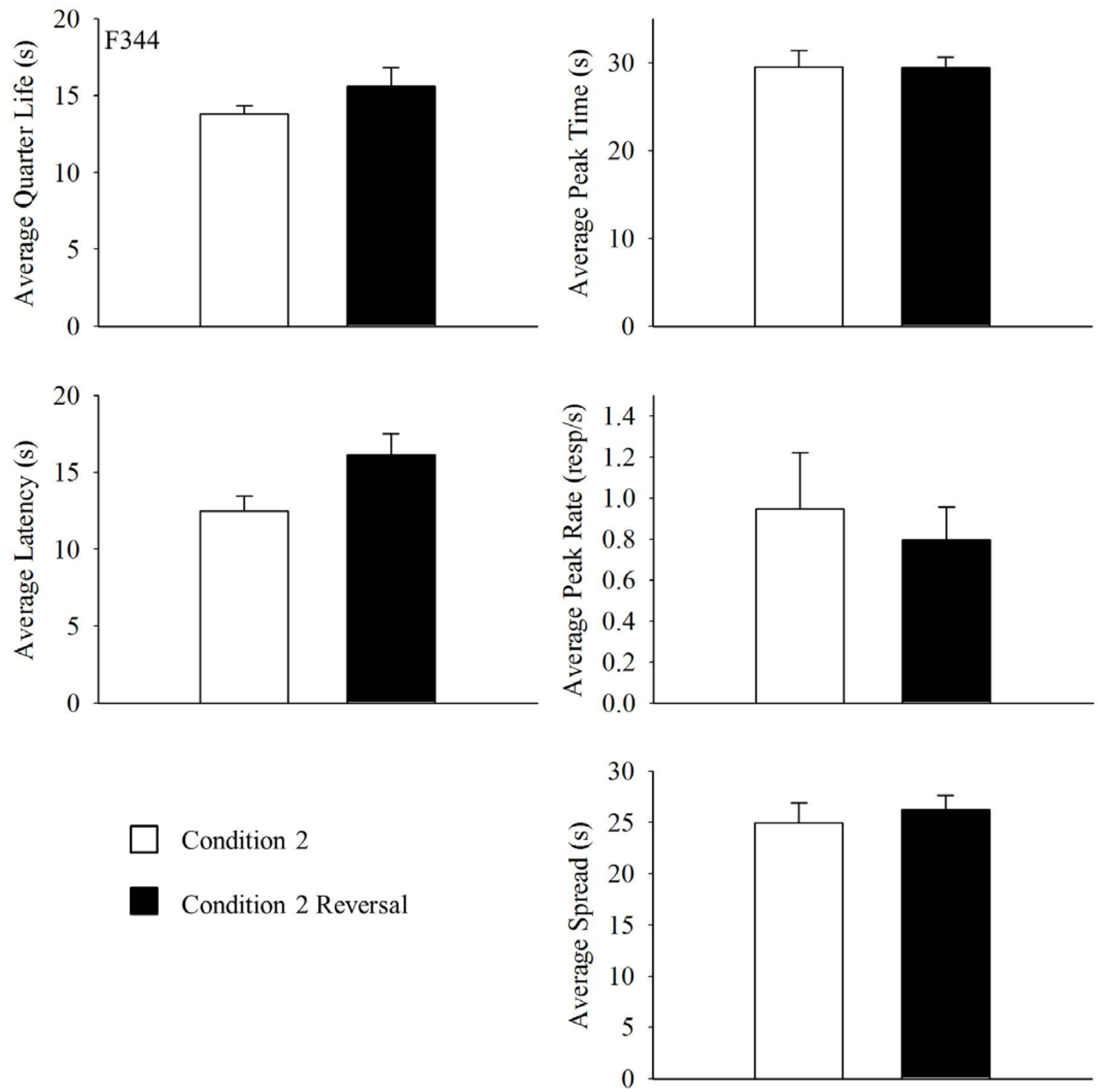

Figure A4. Average data for F344 rats in Condition 2 (white bars) and the Condition 2 Reversal (black bars). The left panel represents FI dependent measures of QL (top) and latency to first response (bottom). The right panel represents PI dependent measures of peak time, peak rate, and spread. Error bars represent standard error of the mean. Note: y-axis scaling differs across measures. 


\section{Appendix B}

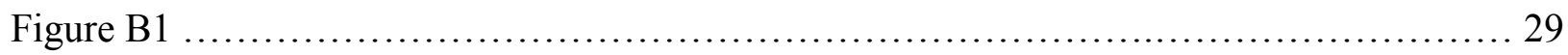

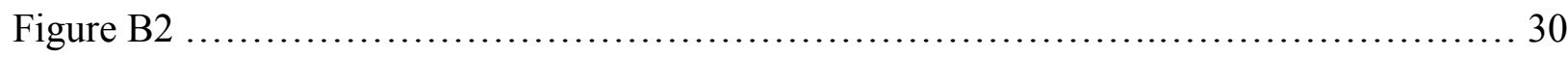

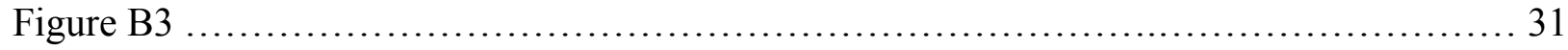

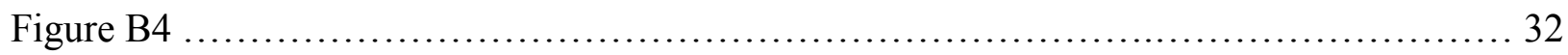

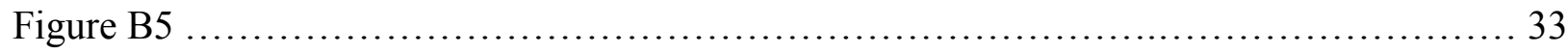

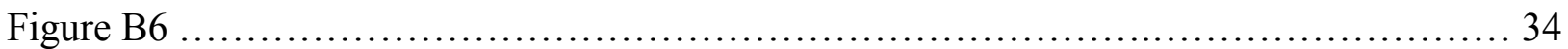



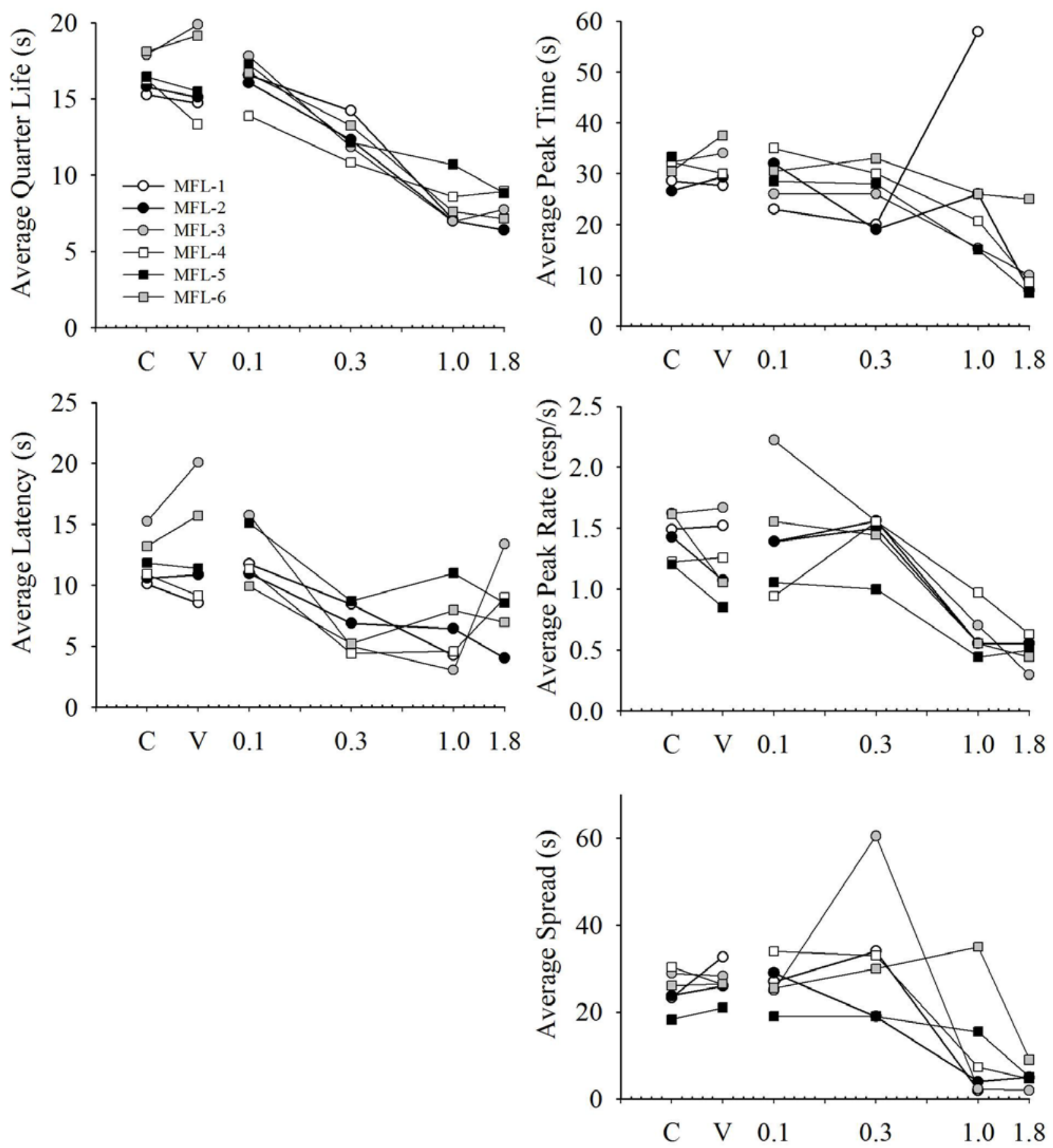

$d$-Amphetamine $(\mathrm{mg} / \mathrm{kg})$

Figure B1. Average dose-response functions for individual LEW rats in the Condition 2 reversal. The left panel represents FI dependent measures of QL (top) and latency to first response (bottom) as a function of $d$-amphetamine dose. The right panel represents PI dependent measures of peak time, peak rate, and spread as a function of $d$-amphetamine dose. Error bars have been removed for ease of viewing general patterns. Note: $y$-axis scaling differs across measures. 

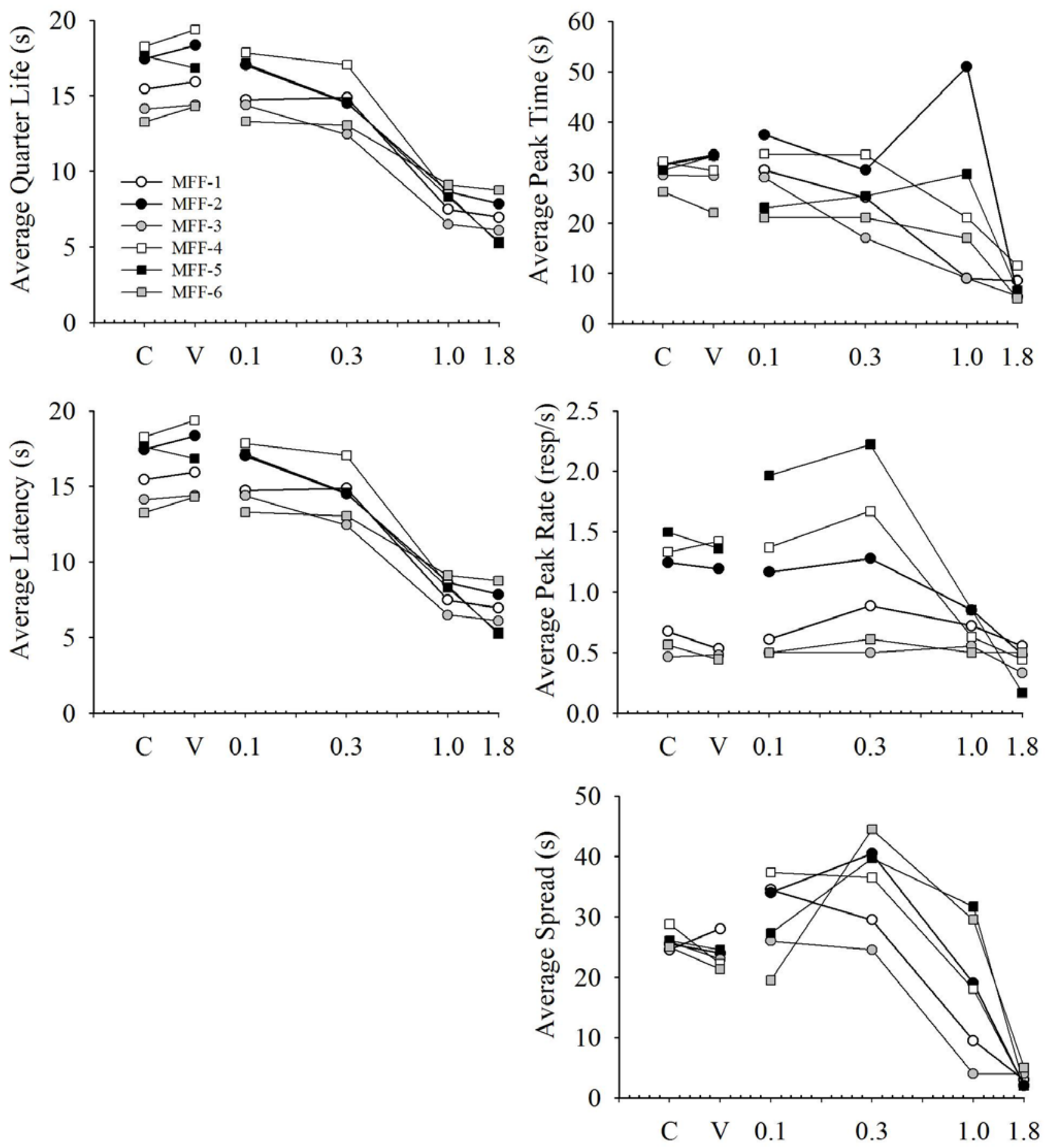

$d$-Amphetamine $(\mathrm{mg} / \mathrm{kg})$

Figure B2. Average dose-response functions for individual F344 rats in the Condition 2 reversal. The left panel represents FI dependent measures of QL (top) and latency to first response (bottom) as a function of $d$-amphetamine dose. The right panel represents PI dependent measures of peak time, peak rate, and spread as a function of $d$-amphetamine dose. Error bars have been removed for ease of viewing general patterns. Note: $y$-axis scaling differs across measures. 

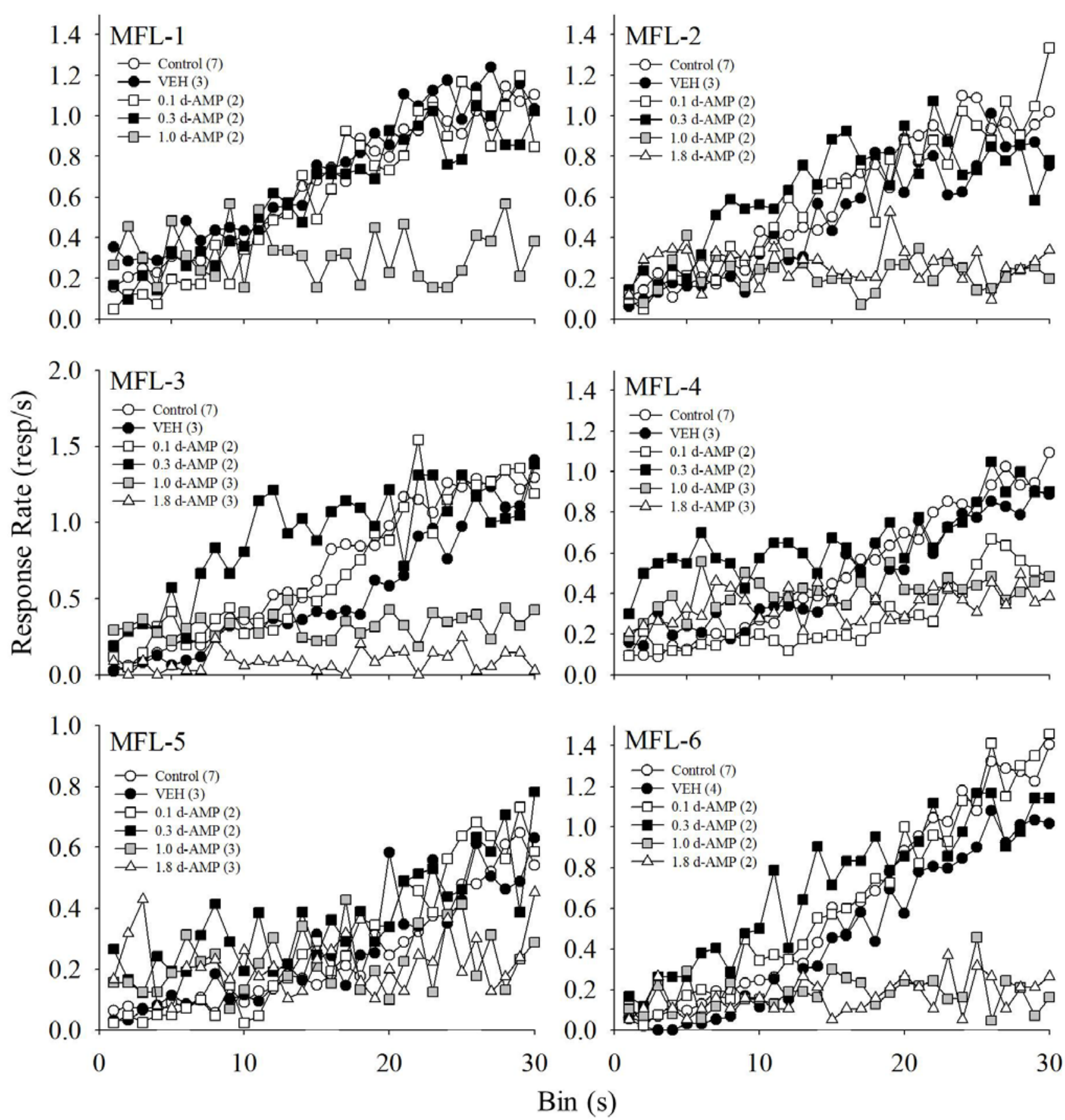

Figure B3.Average response rates for individual LEW rats as a function of time within the FI across doses of $d$-amphetamine. Numbers in parentheses represent the number of determinations of each dose administered. Error bars have been removed for ease of viewing general response patterns. Note: $y$-axis scaling differs across subjects. 

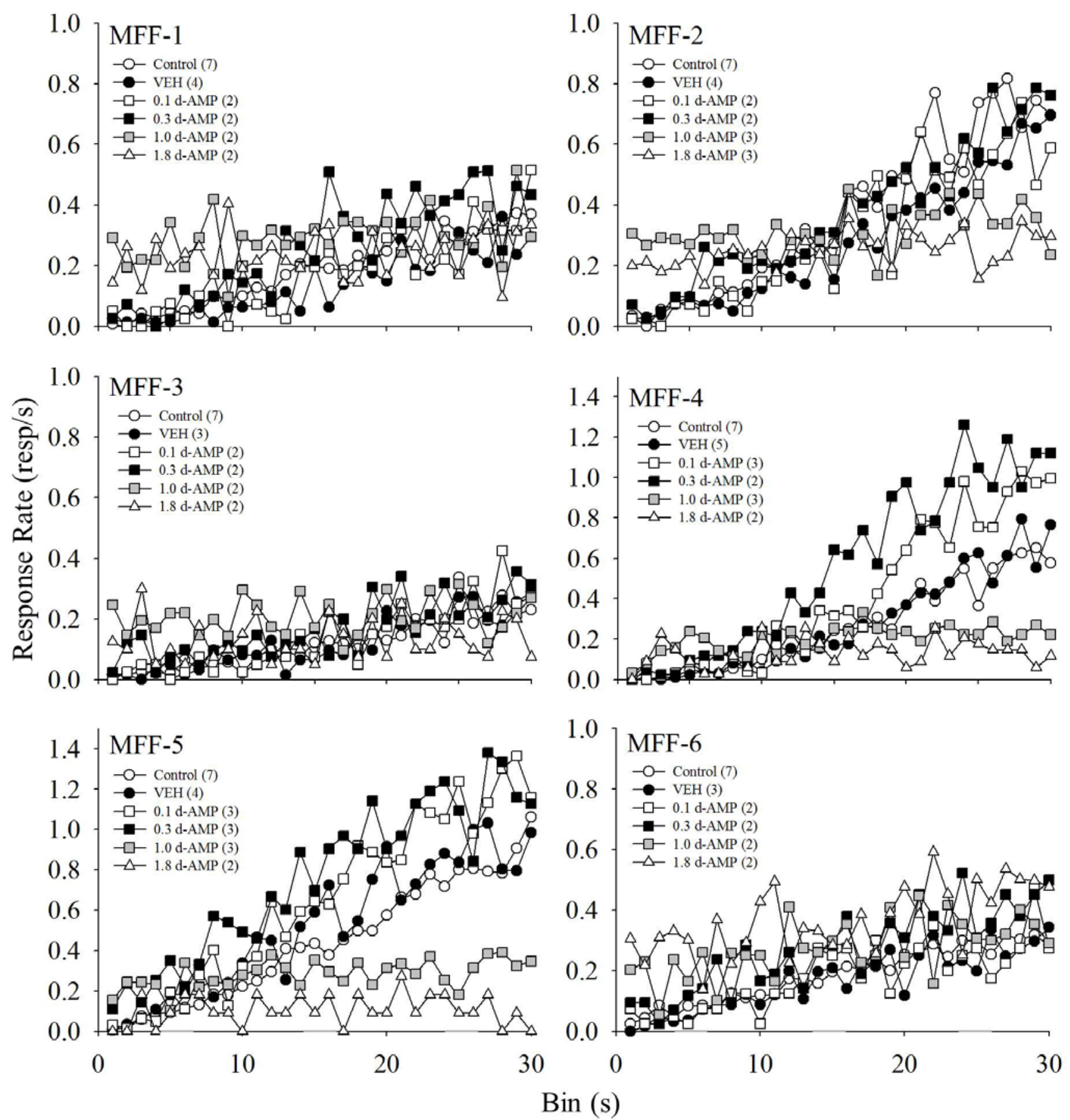

Figure B4.Average response rates for individual F344 rats as a function of time within the FI across doses of $d$-amphetamine. Numbers in parentheses represent the number of determinations of each dose administered. Error bars have been removed for ease of viewing general response patterns. Note: $y$-axis scaling differs across subjects. 


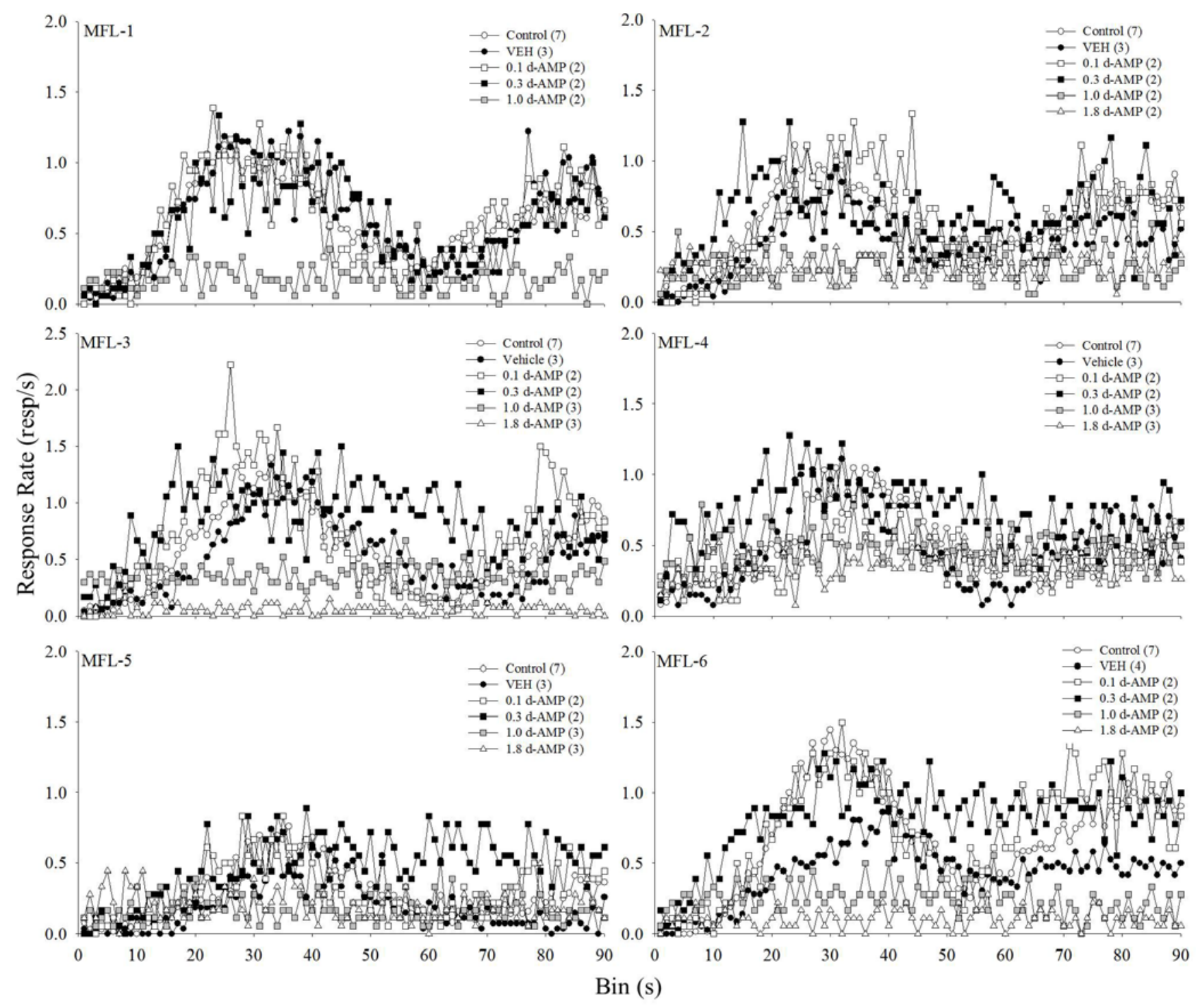

Figure B5. Average response rates for individual LEW rats as a function of time within the PI across doses of $d$-amphetamine. Numbers in parentheses represent the number of determinations of each dose administered. Error bars have been removed for ease of viewing general response patterns. Note: y-axis scaling differs across subjects. 

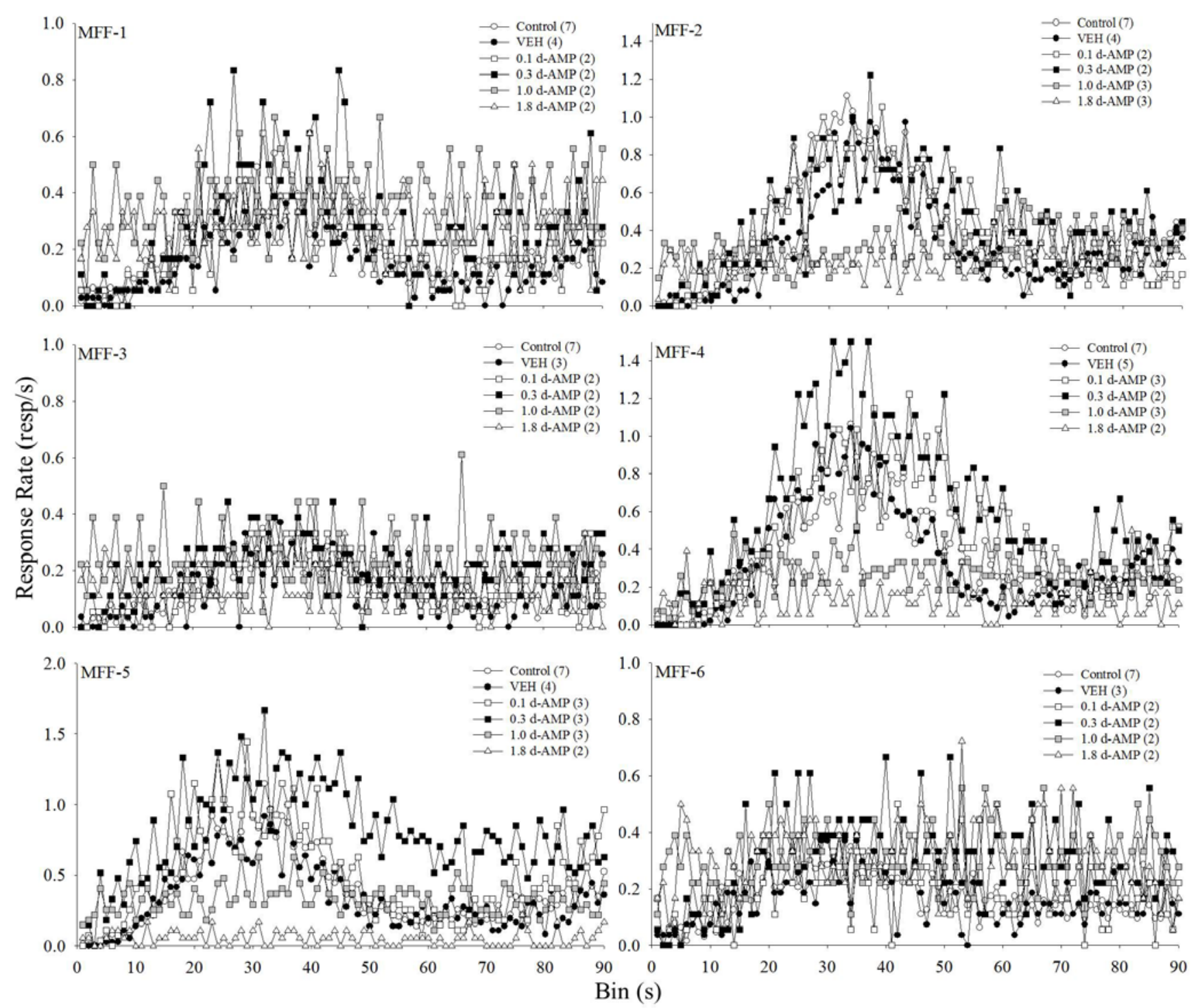

Figure B6. Average response rates for individual F344 rats as a function of time within the PI across doses of $d$-amphetamine. Numbers in parentheses represent the number of determinations of each dose administered. Error bars have been removed for ease of viewing general response patterns. Note: y-axis scaling differs across subjects. 